\title{
Workforce as an Important Factor in Iran's Economic Development
}

\author{
${ }^{1}$ Safdari Mehdi, ${ }^{2}$ Reza Motiee* \\ 1Department of Economics, University of Qom, Iran \\ ${ }^{2}$ Department of Economics, Babol Branch, Islamic Azad University, Babol, Iran \\ *rm.search2011@gmail.com
}

\begin{abstract}
To reach higher economic growth, investment in human capital is also needed besides material investments. The purpose of this study is to determine the relationship between human capital and economic growth in Iran. The theoretical framework was designed based on this assumption that the total human capital employed in the economy is divided into two sections: Human capital with higher education and lack higher education. The data were collected from 1991 to 2006 and were analyzed using Ordinary Least Squares (OLS) model. The result of the analyses showed that there was significant relationship between human capital and economic growth. Together the independent variables explained $94 \%$ of the variance in the dependent variables. The remaining $16 \%$ was due to unidentified variables. In relation to that, we can conclude that explanatory power is high for the equation. It showed that one percent change in human capital rate lead to $58 \%$ in economic growth. Therefore human capital is regarded as an important factor in Iran's economic growth.
\end{abstract}

Key words: human capital, economic growth, co integration and Ordinary Least Squares (OLS) model

\section{Introduction}

Relationship between human capital and economic growth is one of the most important issues in developing countries in recent years and much research has been done (Leamer, 1994). Leamer believed that the distinction between production workers and non-production workers is the wrong benchmark for human resources skills, because being a skilled worker is associated with education, training during work and work experience. According to the importance of human capital in economic growth, many developing countries have attempted to enhance human capital accumulation in their own countries with different styles and especially public support. These efforts are being revealed to be seen easily in these countries increased the average years of education. In such circumstances which had proven a strong positive relationship between per capita income and physical capital accumulation, many studies are considered the question, could affect increasing human capital on growth promotion in these countries? In other words is that, is the causal relationship between human capital and economic growth one-Way relationship of economic growth to human capital? Have considered these countries human capital as a luxury and consumer goods? Few studies about the frequency of countries with concentrated natural resources especially crude oil shows that generally the relationship between human capital and economic growth has been the relationship of unilateral economic growth to human capital and human capital is usually consumed commodity in short and medium term due to rent focus resources and rent state behavior and Dutch disease phenomena and consequences resulting from it in the field of industrial policy and political economy in such countries.

It should be noted that there is disagreement on how to enter human capital in growth pattern. Aghion and Howitt (1998) mention two distinct areas within the endogenous growth literature; Lucas (1988) is one approach and another approach is Nelson and Pheleps (1966). Lucas approach assumes that growth is affected by human capital accumulation. Thus human capital enters in the production function like an ordinary input and in the second approach is linked to of human capital stocks. Nelson and Pheleps (1966) concluded that entering the index of education in production function directly gives incorrect results to identify the relationship between education and production dynamics. This point is confirmed by Benhabib and Spiegel (1994). They concluded that economic growth has no relation to education. Temple (1999) showed that the negative and non-significant learning first order difference coefficient in Benhabib and Spiegel study is because of that they did not enter non-representative of the views in the their study. If abnormal observations will be removed from statistical data, human capital coefficient will be positive and significant. So some researchers obtained a negative relationship between education and economic growth and others obtained meaningless. Therefore we can say that there are three points here: Some have pointed to data quality, some believe the reverse causality and finally, some believe that 
not to enter training leads to results unexpectedly. Lopez et al (1998) believe that the reason empirical research has failed to achieve is that education has not entered in the workforce.

In Iran, the qualitative aspect of the work force in industry does not show much change during the decade in 1991. Three criteria of quality employment (including: workers with the skills and expertise, workers with higher education and workers with experience of more than five years) show little change during a period of six months. In this article we have tried to study the relationship between human capital and economic growth in Iran as an oil-rich country. Therefore, considering the features it human capital training as most important features it and applying the average years of education indicators as an important education process output index, we have investigated the relationship between average years of education and economic growth during 1961-2001.

\section{Human Capital}

Human Resource Productivity: We can say for sure that one of the significant achievements of management and economic knowledge at the moment is the productivity improvement and significant efficiency of two important production factors i.e. human resource and capital is present developed countries. In fact, these countries could improve productivity and efficiency in different parts of industry, services and agriculture by depending on knowledge and proficiency based on progressive and internalized technologies and with the help of management techniques. Thereof, human resource as the main factor in production has a crucial role in economic development and prosperity; thus, economic managers and planners has always cared about human resources productivity of countries, institutions and economic organizations; managers and theoreticians made considerable effort to find practical solutions to increase productivity which is a key factor.

What makes human resources productivity more important is that increasing the productivity of this factor can the increase the productivity of other production factors too and makes optimum utilization of other resources possible. Actually, all know that we can ensure national economic prosperity by planning and implementing effective management and economic strategies and through improving human resources productivity and consequently increasing the productivity of other production factors. Nonetheless, human resources productivity is too low in Iran according to comprehensive studies and official statistics of the International Bank and other international statistical sources. It is interesting to know that the comparison of human resources productivity in Iran with other Asian countries such as Malaysia, Indonesia, Thailand, South Korea and Hong Kong which have similarities with Iran's economy from the viewpoint of development strategies and economic structures, produces warning results.

The Role of Human Resource in Development: Human resources playas an important and crucial role in development process and shapes the future of a country. According to statistics of UNDP (United Nations Development Plan), the role of human resources in national capital is $80 \%$ in Japan, $78 \%$ in Germany and Spain and $72 \%$ in Turkey. National development is a comprehensive process and concerns the improvement of all life aspects of a nation. In addition to improving production and income conditions development brings about fundamental changes in institutional, social and official structures and also in general attitudes of people and even includes people's customs, traditions and beliefs in some cases. In recent decades, special attention was paid to human resources as a smart factor which plays a key role in systems with its skill and innovation. Efficient human resources are counted as the utmost important capital of a country. Basically, knowledge capital is more valuable than production capital. In fact, smart human resources are the main engines of success. Leading organizations are seeking to use minds worldwide and try to find and select the most talented ones as the pivot in the business area of firms. Therefore, we should regard human resources as the pivot of development to reach stable development and should make the largest investments on human resources as it was done by some Third World countries like South Korea, China and Malaysia to reach development in the new wave. In the Human development Report in 2004, Iran moved up five places and was the $101^{\text {st }}$ in the rankings.

Human Resources Skill in Economic Growth: Economists have different attitudes towards the effect of training and developing human resources and believe that production output will increase both qualitatively and quantitatively by considering and emphasizing on specialized training of the workforce. Dividing the production technology into labor-intensive technology which involves the labor force and capital-intensive technology which involves machinery and capital-intensive methods of production, some experts concluded that human resources are the main factors of production in both production 
technology methods, and human resources are more than $80 \%$ effective on production in some countries like South Korea and Japan. In fact, technology comes from the intelligence, capabilities, innovation and productivity of human resources in the work process. In today's competitive world, success cannot be achieved without research and development because machinery, technology and production methods are improving day by day and the researcher human resources are needed as well as machinery to improve production. With regard to the large share of labor-intensive technology in Iran's economy and industry, and as the largest part of the production depends on the workforce, the role of training, human capital, felicity and motivation in workforce and reducing stresses should be emphasized for higher growth in the country.

Since no accurate statistics available for employees each year separately, thus the time change direction for labor productivity is not available in economic of Iran but can be searched development it. In Iran's economy labor productivity increase with high fixed rate during the period of 1976-1966 and it decrease at first in the period after the revolution and then increases. Table 1 show that in the period 1966-1978 productivity growth rate have been fluctuated around the constant mean but average growth has changed after the Revolution.

\begin{tabular}{ccccc}
\multicolumn{6}{l}{ Table 1: Evolution of labor productivity in Iran's economy } & (million IRR') & \\
\hline years & $\begin{array}{c}\text { Workforce } \\
\text { productivity fixed } \\
\text { price in 1997 }\end{array}$ & $\begin{array}{c}\text { Average years of } \\
\text { workforce } \\
\text { education }\end{array}$ & $\begin{array}{c}\text { The Gini } \\
\text { coefficient in } \\
\text { education }\end{array}$ & $\begin{array}{c}\text { Workforce per } \\
\text { capital stocks }\end{array}$ \\
\hline 1966 & 11.2 & 1.52 & 0.8308 & 21.5 \\
1976 & 27.54 & 2.77 & 0.7372 & 65.5 \\
1986 & 17.56 & 4.43 & 0.5972 & 87.3 \\
1991 & 18.7 & 5.38 & 0.5171 & 77.6 \\
1996 & 19.5 & 6.2 & 0.4587 & 75.7 \\
2000 & 19.4 & 6.74 & 0.4369 & 74.7 \\
\hline
\end{tabular}

Source: National Accounts of Iran (1956-2000), central bank of Iran

Human Development and Export: Human resources play a significant role in increasing production level and optimum utilization of resources. According to present indices, development evaluation of a country depends on the role of human resources capital in creating value added. As employment is one of the main concerns of policy makers, planners and governors of the country, one of the missions of the government and civil groups is to provide necessary bases for the participation of experts in different jobs and economic activities. Using traditional methods in different production sectors and the absence of experts and specialists in all economic areas caused the value added in different sectors of the country's economy not be at an acceptable level; therefore, Iran is gradually losing its competitive edge. Having a look at the non-oil goods export of Iran shows that one third of them is composed of traditional goods that a significant part is dedicated to agricultural products. Looking into the agricultural sector which provided one third of the country's employment and form 25 percent of GNP reveals that the yield rate of this sector is not at an appropriate level due to not using modern technologies, experts and specialist in agriculture, farming and gardening.

Economic experts believe that competitive production and supply in international markets are important to boost non-oil export and it depends on both quality improvement and price reduction. Quality improvement requires using modern knowledge and technologies which can be made possible by our competent experts and specialists; price reduction through offering at competitive prices requires efficiency enhancement especially human resources efficiency. Hence, human resources development to boost export is very important in addition to some other factors such as creating suitable economic structures, preparing legal bases, avoiding too strict laws and monetary, financial and foreign exchange reformations. Some experts believe that most serious challenges to the research section of the country are determining technical-scientific status of the country, making changes in scientific-academic fields, increasing the effectiveness of scientific and research sources and improving productivity. Also, technological and scientific development helps to cost and time reduction, efficiency enhancement, quality improvement. It is certain that the position of human resources is not known in our economy and non-oil exports yet and even is not clarified in the development of the oil industry which has fed the country's economy for more than fifty years. Removing present obstacles and limitations is only possible

\footnotetext{
${ }^{1}$ IRR is monetary unit in Iran. Based on ISO-4217 standard Iran's Rial is shown with the symbol IRR In global trading.
} 
through a proper perspective of goals. We can even target plans for qualitative and quantitative population control and provide the opportunity for a high quality and proper life for people. Moving and investment in vague conditions leads to the waste of resources, time and losing golden chances for developing national economy and finding the suitable position for Iran and Iranians in the world.

The following table shows the status indicators of value added, employment and labor productivity in economic sectors in the years (2000-2007), which is given for comparison below:

Table 2: Status indicators of value added, employment and labor productivity in economic Sectors in the years (2000-2007)

\begin{tabular}{lccc}
\hline \multicolumn{1}{c}{ Year } & $\begin{array}{c}\text { Agricultural } \\
\text { Sector }\end{array}$ & $\begin{array}{c}\text { Oil and Gas } \\
\text { sector }\end{array}$ & $\begin{array}{c}\text { Industry and } \\
\text { mining }\end{array}$ \\
\hline \%Value added growth & 4.9 & 3 & 11.3 \\
\%Employment growth & 1.5 & 1.2 & 3.6 \\
$\begin{array}{l}\text { The average employment share } \\
\text { of this part of total }\end{array}$ & 15.5 & 0.6 & 16.6 \\
\%Labor productivity growth & 3.4 & 1.7 & 7.5 \\
\hline
\end{tabular}

\section{The Previous Studies}

Grilichz (1964) imported training in the production function as production inputs and concluded that this is an important variable. Raymo (1995) examined the role of human capital on economic growth in Japan during the period 1970-1991 and concluded that to obtain share it in Gross Domestic Product (GDP). Based on his opinion, production function in general form is following: $Y=f(K, L, H K)$ where $Y$ is Gross Domestic Product (GDP), $L$ is full employment and $K$ is human capital. Here is the production function as Kab Daglas function and is assumed that efficient to scale is fixed and is defined in the following: $Y=A K^{\alpha}$ $L^{\beta} H K^{\gamma} e^{\varepsilon}$, then obtained to an equation be estimated by logarithm of Kab Daglas function in the following: $\operatorname{Ln} Y=\operatorname{Ln} A+\alpha \operatorname{LnK}+\beta \operatorname{Ln} L+\gamma \operatorname{Ln} H K+\varepsilon$, and concluded that expenditure spent on Training and average years of education for workforce have a positive and significant impact on the economic growth in Japan as two indicators of human capital.

Denison (1967) believed that quality of human labor is improve by human capital and concluded that growth of formal education explain $25 \%$ of the per capita income growth for the people of America during the period of (1929-1982) in America. Hojo (2003) believed that processing Impact of training on economic growth is indirectly so that there is a meaningless relationship between training and economic growth and concluded that training affects on the growth by increasing productivity i.e. rising cost of training leads to increased manufacturing productivity and since productivity is high due to high growth, so training costs have indirect and positive effect on economic growth rate in countries. Oketch (2006) reviewed the role of human capital on improving economic efficiency in African countries. This study tries to the following: 1) Relationship between developments of human capital generated in formal schools and economic growth 2) Relationship between investment on physical capital and economic growth. He concluded by two Stage Least Square (2SLS) that physical and human investment in Africa is essential for industrial development as engines of growth in these countries.

\section{Research Methodology}

Considering the various studies that have done labor variable in production function is proposed in this study Kab Daglas model ${ }^{1}$ that has been diagnosed as best function in terms of consistent and compatible with economic conditions. Production Function Kab Daglas is very simple and very common form of production function gives the following:

$\mathrm{Q}=\mathrm{AK}^{\alpha} \mathrm{L}^{\beta}$

Where $\mathrm{A}$ is coefficient technology, $\mathrm{K}$ physical capital, $\mathrm{L}$ force work and $\alpha, \beta$ Demonstrate to the capital elasticity of production and work. $\alpha+\beta$ is represent homogeneous, because:

$$
\mathrm{F}(\lambda \mathrm{K}, \lambda \mathrm{L})=\mathrm{A}(\lambda \mathrm{K})^{\alpha}(\lambda \mathrm{L})^{\beta}=\lambda^{\alpha+\beta} \mathrm{AK}^{\alpha} \mathrm{L}^{\beta}=\lambda^{\alpha+\beta} \mathrm{Q}
$$

\footnotetext{
${ }^{1}$ Retrieved from Raymo (1995).
} 
So when the function is $\alpha+\beta=1$, kab daglas model shows constant returns to scale. Per capita, which is written as $\mathrm{q}+\mathrm{AK}^{\alpha}$ ?

$$
\begin{aligned}
& \frac{\partial Q}{\partial K}=a A K^{\alpha-1}=a \frac{Q}{K} \\
& \frac{\partial Q}{\partial L}=\beta A K^{\alpha} L^{\beta-1}=\beta \frac{Q}{L}
\end{aligned}
$$

Thus $\alpha, \beta$ demonstrate to the capital elasticity of production and work.

\section{Results}

Unit root test by Augmented Dickey - Fuller (ADF) and Philips - Perron: Employing the traditional methods econometric for experimental work is based on stationary assumption for variables but surveys done show that this assumption is incorrect and variables are more non stationary. Thus based on the co integration theory, it is necessary to review stationary and non stationary for variables. Therefore we use (ADF) and Philips - Perron tests and choose the length of optimal lag based on Schwarz Bayesian (SBC) in the following table:

Table 3: Result of unit root tests by ADF and Philips - Perron

\begin{tabular}{cccc}
\hline Variables & (ADF) test & Philips - Perron test & result \\
\hline $\mathrm{L}(\mathrm{Q} / \mathrm{L})$ & $\mathrm{ADF}(1)=-1.25$ & -1.59 & Non stationary \\
5\% Critical Value & -2.94 & -2.94 & \\
DL $(\mathrm{Q} / \mathrm{L})$ & $\mathrm{ADF}(0)=-3.32$ & -3.54 & Stationary \\
5\% Critical Value & -2.94 & -2.94 & \\
L (K/L) & $\mathrm{ADF}(1)=-1.67$ & -1.89 & Non stationary \\
5\% Critical Value & -2.94 & -2.94 & \\
DL (K/L) & $\mathrm{ADF}(0)=-3.39$ & -3.44 & Stationary \\
5\% Critical Value & -2.94 & -2.94 & \\
L (H/L) & $\mathrm{ADF}(0)=-3.65$ & -3.97 & Stationary \\
5\% Critical Value & -2.94 & -2.94 & Non stationary \\
L (TR) & $\mathrm{ADF}(1)=-1.81$ & -2.08 & \\
5\% Critical Value & -2.94 & -2.94 & Stationary \\
DL (TR) & $\mathrm{ADF}(0)=-4.32$ & -3.78 & \\
5\% Critical Value & -2.94 & -2.94 & \\
\hline
\end{tabular}

Table 3 shows that all variables are non stationary (except $\mathrm{H} / \mathrm{L}$ ) and will be stationary with once making difference. Therefore $\mathrm{L} / \mathrm{H}$ variable is accumulation of degree zero (I (0)) and other variables are one accumulated degree (I (1)).

Estimating Model: In this section, the total workforce employed in the economy, we have divided into two sections with higher education and workforce lacking, and the production per capita has also used the whole economy of production. The purpose of the indicators selected is that to answer these questions: 1) has the impact higher education in production and economic growth as instead of human capital? 2) How influential is it? Here, we wanted to show the impact on human resources development specialist entire economy, the resulting equation is estimated:

$$
\begin{gathered}
\log \left(\frac{Q}{L}\right)=0.54 \log \left(\frac{K}{L}\right)+0.58 \log \left(\frac{H}{L}\right)-0.07 T R+0.8 M A(1)+0.45 M A(2) \\
(1.99) \quad(9.987)(-11.574) \quad(5.645) \\
\mathrm{F}=187 \quad \text { D. } \mathrm{W}=2.02 \quad \quad \mathrm{R}^{2}=0.94
\end{gathered}
$$

Here, the coefficient of human capital, i.e. highly educated employees, which is 0.58 suggests a strong and positive impact on economic growth force, and shows a percentage increase in the number of employees with higher education studies can increase 0.58 percent economic growth. Coefficient of physical capital is 0.54 , but the associated t statistics to show that this coefficient is acceptable with 97 percent probability. 


\section{Conclusion, Discussion and Recommendations}

The estimated model states that there is a positive and meaningful relationship labor (as educated employees) and physical capital stock on Gross Domestic Product (GDP) that is consistent with theoretical expectations. The estimated coefficients are signs of elasticity of production factors and express that increase in the workforce as one percent leads to 0.58 percent increase in the GDP and also increase in the physical capital as one percent leads to 0.54 percent increase in the GDP. According to the results obtained human capital has a positive effect on GDP as an important and effective variable in the long run. Therefore can be say, since there is a relationship between educated employees and workforce skills consequently has more effect on GDP.

The analysis of variance shows that in the short term forecast variance error in GDP is explained by itself and in the long run is reduced the amount of it and labor, physical capital and human capital variables explain forecast error in the GDP. Since human capital in the long run is more than short-term could explain forecast error in the GDP, Consequently we can say that the effect of human capital on GDP is a long-term process. So we can conclude in the following: 1) Processing impact of human capital on production is a long run process, 2) rate and how much influence human capital on GDP depends on indices used for human capital. So it is reasonable to survey influence of human capital on growth and production with emphasis on indicators used for human capital.

Economists have tries in many different ways to evaluate investment costs and benefits in human resources. After all, Ordinary Least Square (OLS) was used regarding the purpose of this research i.e. studying the role of human capital in GNP to measure the change in dependant variable after changing a variable by one unit. The results of these estimations about human capital show this important point that the human capital factor is a stable and meaningful factor with a positive coefficient in all equations which shows the positive effect of human capital on output. Coefficient of workforce in this system implies the labor-intensive production i.e. products are less capital-intensive than human capital. Consequently, one of the main and crucial factors in inefficiency is the improper utilization of productive capacity in which we should also seek technologic changelessness in the country's production. Training is an important factor in human resources productivity improvement in producing goods and services which causes growth. We should also mention that we should also pay attention to training during work, vocational and technical trainings and public advanced trainings; the last one is only limited to staff in Iran and has not been put into action yet. Since human capital (educated sector) is the effective factors on GDP and also has a positive effect with more time lag on GDP, so is recommended to reduce the time lag by improving quality of workforce Training and implementing policies that lead to accelerating the positive effects of human capital on GDP.

\section{References}

Aghion, P. and Howitt, P. (1998). Endogenous Growth Theory. MIT Press, Cambridge, Mass.

Benhabib, J. and Spiegel, M. (1994). The Role of Human Capital in Economic Development: Evidence from Aggregate Cross-Country Data. Journal of Monetary Economics, 34(2): 143-173.

Denison, E. (1967). Why growth rates differ. Past war Experiences Nine Western countries, Washington, D.C.: Brooking.

Griliches, Z. (1964). Research Expenditures, Education and the Aggregate Agricultural Production Function. American Economic Review, 54(6): 961-974.

Hojo, M. (2003). An Indirect Effect of Education on Growth. Economics Letters, Vol. 80(1), 31-34.

Leamer, E., E. (1994). Trade, wages and the revolving door ideas. NBER working paper. No, 4716.

Lopez, R., Vinold, T. and Wang, Y. (1998). Addressing the Education Puzzle: The Distribution of Education and Economic Reforms. World Bank.

Lucas, R. (1988). On the mechanics of economic development. Journal of Monetary Economics, 22(1): 3-42.

Nelson, R. and Phelps, E. (1966). Investment in humans, technological diffusions and economic growth. American Economic Review: Papers and Proceedings, 51(2): 69-75.

Oketch, M., 0. (2006). Determinants of human capital formation and economic growth of African countries. Economics of Education Review, 25: 554-564.

Perron, P. (1989). The Great Crash, the Oil Price Shock and the Unit Root Hypothesis Econometrica, 57(6): 1361-1401. 
Raymo, J. (1995). Are Investments in Higher Education Productive? Evidence from Japanese time series data. Osaka City University Economic Review, 30(1): 53-64.

Temple, J. (1999). A positive Effect of Human Capital on Growth. Economics Letters, 65(1): 131-134. 